\title{
Advances in Minimal Cell Models: a New Approach to Synthetic Biology and Origin of Life
}

\author{
Pasquale Stano \\ Biology Department, University of Roma Tre \\ Italy
}

\section{Introduction}

Minimal cells can be defined as those compartment-based systems containing the minimal and sufficient number of molecular components and still displaying the essential features (structure and functions) of natural living cells (Luisi et al., 2006). The research on minimal cells, in recent years, has attracted the attention of several groups, as witnessed by the increasing number of reports and reviews published on the subject, as well as a dedicated book (Stano \& Luisi, 2011).

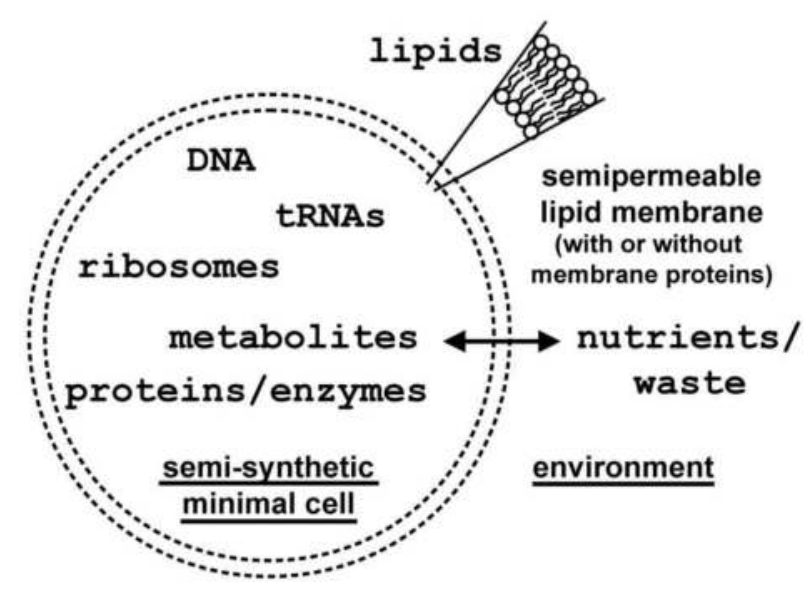

Fig. 1. Semi-synthetic minimal cells (SSMCs). The minimal number of genes, enzymes, RNAs, and low molecular-weight compounds are encapsulated into synthetic lipid-based compartments, such as in the case of lipid vesicles. The membrane acts as a boundary to confine the interacting internalized molecules, so that a "unit" is defined. Moreover, its semi-permeable character (possibly modulated thanks to the insertion of membrane proteins acting as selective pores, as in the case of hemolysin (Noireaux \& Libchaber, 2004) or porins (Graff et al., 2001; Vamvakaki et al., 2005; Yoshimoto et al., 2005) allows the material exchange between the SSMC and its environment (nutrients uptake, waste release). 
The concept of minimal cell in biology, however, is not new. Looking at the astonishing genetic and metabolic complexity of simplest living organisms, such as unicellular microbes, one might ask whether such complexity is really a necessary condition for life, or whether life is compatible with a simplest organization (Morowitz, 1992; Knoll et al., 1999). This question has its root in the field of origin and evolution of life, considering that modern sophisticated cells derive from million years of evolution, and that primitive cell could not be as complex as modern ones. Together with a theoretical approach, an experimental approach is needed to investigate the realm of minimal cells. Initially developed within the origin of life community, the construction of minimal cell models not only tries to answer the question of the minimal complexity for living organisms, but also focuses on the assembly steps (from separated molecules to organized compartments). At this aim, several studies have been carried out to build, like a chemist would do, minimal cell models from an appropriate compartment (such as micelles, or vesicles) and certain solutes. In addition to studies where very simple chemicals are used for building such structures, particularly promising seems the use of enzymes, RNAs, DNAs. In fact, it is easier to build typical cell functions from these "modern" components (Fig. 1). When evolved molecules, as those listed above, are used to construct a minimal cell in a synthetic compartment, such as a lipid vesicle, it is convenient to call these constructions as "semi-synthetic" minimal cells (SSMCs).

More recently, however, the "minimal cell project" became one of the well-recognized topics of synthetic biology (De Lorenzo \& Danchin, 2008), where - however - it might assume a slightly different connotation. In fact, top-down approaches, typical of this new discipline, aim at reducing the complexity of extant cells by removing unessential parts, typically by genetic engineering and metabolic engineering. The progress in genome synthesis brought about the assembly of a synthetic genome, which has then transferred to a genome-deprived cell (Gibson et al., 2010). On the other hand, the semi-synthetic approach - which is discussed in this review - can be classified as bottom-up, because it starts from simple molecules and aims at constructing a cell. In the following, we will first introduce the theoretical framework for understanding what is the essential dynamics of a living cell, then quickly review some aspects of the minimal genome, and later discuss in details some recent experimental studies. Finally, we will see how SSMCs could be used in the future as biotechnological tool.

\section{Minimal life from the autopoietic perspective}

The starting point for the analysis of minimal living properties is the theory of autopoiesis (self-production). Developed by Humberto Maturana and Francisco Varela in the Seventies (Varela et al., 1974), autopoiesis is a theory that focuses on the essential dynamics of a single cell. It does not describe how a cell originates, but just how it functions. First of all it is recognized that a cell is a confined system composed by interacting molecules, and that the essential feature of a living cell is the maintenance of its own individuality. Several transformations take place inside its boundary. Thanks to the continuous construction and replacement of internal components (boundary molecules included), and thank to this internal activity only, the cell maintains its state within a range of parameters, which are compatible with the existence and the good functioning of the set of transformation occurring inside. So, despite the continuous regeneration of all its parts, an autopoietic cell maintains its individuality because the structural and functional organizations do not 
change. What is continuously changed is the material implementation of these organizations. It is easy to draw a minimal autopoietic unit that obeys to this mechanism (Fig. 2).

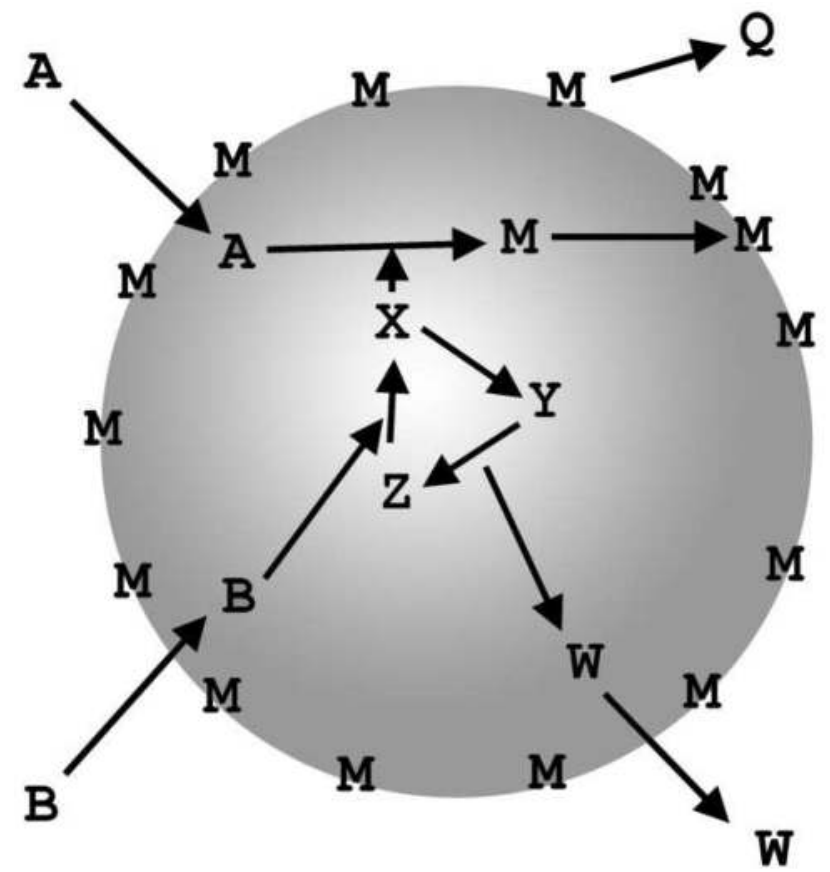

Fig. 2. Autopoietic dynamics as a guiding framework for constructing minimal cells. A set of compounds, here called $\mathrm{M}, \mathrm{X}, \mathrm{Y}$, and $\mathrm{Z}$ are assembled in a self-bounded structure, i.e., a celllike compartment. The functional and structural organization of these components foresees that $\mathrm{X}, \mathrm{Y}$, and $\mathrm{Z}$ act as mutual catalysts for their own production, and moreover $\mathrm{X}$ acts as catalyst for the formation of $\mathrm{M}$ (the boundary-forming component). Overall, this establishes a self-maintenance self-producing dynamics, based on chemical reactions and self-assembly, where all components of the autopoietic unit are generated from the autopoietic network and inside the autopoietic structure. In order to function, the autopoietic unit needs to uptake precursors from the environment $(A, B)$, and release waste products $(Q, W)$, therefore working as an open system. An autopoietic unit is in homeostatic regime when the rate of components building is equal to the rate of their decay.

Notice that in autopoiesis there is no need to specify the role of DNA, RNA, etc., these molecules act as elements of the internal networks aiming to keep the dynamic organization of internal transformations. The blueprint for the cell life consists of processes that produce all cell components that in turn produce the processes that produce such components, ... Clearly, all this occurs at the expense of energy and nutrients from the environment, so that the living cell is, thermodynamically speaking, an open system, yet characterized by its own operational closure (no external information is needed to organize and reproduce itself from inside). 
The first attempts to create a minimal chemical autopoietic systems were done with simple supramolecular systems as micelles and reverse micelles, and later on with vesicles (for a recent review, see Stano \& Luisi (2010a). The comment on such systems is outside the scope of this chapter, but it is useful to say that the current research of SSMCs construction still relies on the autopoiesis as a theoretical framework. The initial micelle/vesicle systems are taken as basic model to develop more complex design, based on the general scheme of Fig. 2, by substituting the abstract $\mathrm{X}, \mathrm{Y}, \mathrm{Z}$, and $\mathrm{M}$ components with real (bio)chemical species that are able to function as a network of minimal complexity.

\section{Minimal genome}

\begin{tabular}{|l|c|c|c|}
\hline & $\begin{array}{c}\text { Mushegian } \\
\text { \& Koonin, } \\
1999\end{array}$ & $\begin{array}{c}\text { Gil et al., } \\
2004\end{array}$ & $\begin{array}{c}\text { Forster \& } \\
\text { Church, 2006 }\end{array}$ \\
\hline Amino acids and derivatives & 3 & 0 & 0 \\
\hline Carbohydrate metabolism & 21 & 14 & 0 \\
\hline Cell division and cell cycle & 7 & 9 & 0 \\
\hline Cell wall and capsule & 6 & 0 & 0 \\
\hline $\begin{array}{l}\text { Cofactors, vitamins, prosthetic groups, } \\
\text { pigments }\end{array}$ & 8 & 15 & 0 \\
\hline DNA recombination and repair & 5 & 3 & 0 \\
\hline DNA replication machinery & 17 & 17 & 4 \\
\hline Electron transport chain & 10 & 9 & 0 \\
\hline Fatty acids and lipids & 7 & 7 & 0 \\
\hline Nucleoside and nucleotides & 21 & 15 & 0 \\
\hline Protein biosynthesis & 76 & 67 & 71 \\
\hline Protein folding & 9 & 5 & 2 \\
\hline Protein turnover & 1 & 2 & 0 \\
\hline RNA processing and modification & 2 & 3 & 2 \\
\hline Transcription machinery & 19 & 7 & 4 \\
\hline Transmembrane transport & 26 & 27 & 0 \\
\hline tRNA synthesis and modification & 6 & 4 & 25 \\
\hline Unclear/uncharacterized functions & 251 & 208 & 109 \\
\hline TOTAL & 7 & 4 & 0 \\
\hline
\end{tabular}

Table 1. Comparison of three different versions of the "minimal genome". Adapted with minor modifications (additional columns have been removed) from Henry et al. (2010), with permission from Wiley.

When we ask how a SSMCs can be constructed, we look at what are the minimal number of functions that have to be implemented into a minimal cell. The concept of "minimal 
genome" is clearly linked to this aspect. If we would like to employ proteins as functioncarrying molecules, the only way we know for generating them is decoding the DNA sequence. So, specifying what is the minimal number of functions in a minimal cell is equivalent to specify the minimal number of genes required to codify such functions. The concept of minimal genome is also a very well discussed topic in biology. Several studies and reviews have been published (Mushegian \& Koonin, 1996; Gil et al., 2004; Islas et al., 2004; Forster \& Church, 2006; Fehér et al., 2007; Moya et al., 2009; Henry et al., 2010). Mycoplasma genitalium genome (482 genes) is the smallest organism that can be grown in pure colture (Fraser et al., 1995). This means that its genome encodes for all functions required to sustain life at the cellular level. By comparing $M$. genitalium genome with those of other small microorganisms (endosymbionts such as Buchnera, or parasites as Haemophilus influenzae are taken into account) several studies have been published in order to find the common genes. The first minimal gene set (of about 250 genes) was generated by Mushegian \& Koonin (1996), who compared M. genitalium and H. influenzae genomes, the only ones available at that time. In 2004, Moya and coworkers (Gil et al., 2004) performed a combined study including the comparison of reduced genomes from insect endosymbionts (Buchnera), reaching the conclusion that the minimal gene set is composed of about 200 genes. More recently, Forster \& Church (2006) searched for the biochemical description of well-defined pathways that are needed to perform essential functions: in this way they describe a minimal gene set of about 100 genes. A comparison among these three minimal gene sets is shown in Table 1.

As it can be seen, the largest group of genes refers to protein biosynthesis, a pathway that involves the ribosomes, the essential and complex molecular machine that is the very cornerstone of cell function. tRNA-related genes are also numerous, as well as DNA replication. It is clear that the minimal genome essentially encodes the instruction for translating and duplicating the genetic information. Consider for example that in very permissive conditions a minimal cell could take energy and low molecular weight compounds from the environment, so that all genes required to accomplish these functions can be removed from the list of Table 1. It is evident that the essential part of the genome is that one dedicated to the production of internal components that reciprocally produce each other (from DNA to protein, from protein to DNA), plus those dedicated for boundary production, as requested by the autopoietic theory. In other words, under the constrains of current biochemical routes, the minimal genome should correspond to the minimal circuitry needed to establish a self-maintenance autopoietic dynamics. A further simplification would be possible only by removing these constraints, for example (hypothetically) by reducing the number of amino acids, or using a single enzyme for carrying out multiple functions, or by reducing the complexity of ribosomes.

Even considering the very small number of ca. 100 genes (Forster \& Church, 2006), it is probably difficult to imagine the construction of a viable minimal cell. To date, the figure of 100 genes is still far beyond the current experimental approaches, where, as it will be shown in next paragraphs, a maximum of two genes have been simultaneously expressed inside lipid vesicles.

To conclude, it is useful to remark that the goal of defining (and synthesizing) a minimal genome can have - in addition to the theoretical conclusions for minimal cell bottom-up studies - some practical applications, especially in synthetic biology. For example, Henry et al. (2010) emphasize that the creation of a minimal organism (intended here as derived from the top-down approach) could be significant; for example the lack of mobile DNA elements 
might alleviate difficulties in controlling industrial bacteria strains; the lack of competing metabolic pathways might increase the net conversion yield of a desired product, or avoid the production of toxic side-products; the reduction of transcriptional regulation might favor the efforts to engineer minimal microorganisms.

\section{A roadmap to the construction of minimal cells}

The minimal genome analysis shown in the previous section has revealed that in order to build a SSMC - possibly living, although certainly "limping" (Luisi et al., 2006) - about 100 different genes must be encapsulated into lipid vesicles, and all of them must be transcripted and translated into functional proteins. At this aim, a new technology must be developed. To date, this technology comes from the convergence of in vitro cell-free systems and liposome technologies (Fig. 3A). Possibly, in the near future an key role could be played by microfluidics, which is experiencing a very strong growth with applications to several analytic and synthetic questions. In particular, the recent reports on the controlled formation of giant vesicles (GVs) inside (or with the help of) microfluidic devices is an interesting innovation (Walde et al., 2010; Sugiura et al., 2008; Ota et al., 2009; Matosevic \& Paegel, 2011). From a more general viewpoint, one can imagine a sort of roadmap that leads to advanced minimal cell models, starting from very basic and already available technology (Fig. 3B).

The zero-th step is clearly the control of liposome technology, in terms of liposome formation and manipulation methods, solute encapsulation, and detection methods. This will be discussed more in details in next paragraph.

Then we can imagine a stepwise advancement, from simple enzyme-inside-vesicle systems to more elaborated ones, based on gene expression inside vesicles. Investigation on oneenzyme-containing vesicles is already well developed, and a variety of enzymes have been entrapped into lipid vesicles (alkaline phosphatase, amylase, asparaginase, chymotrypsin, elastase, galactosidase, lysozyme, pepsin, perossidase, glucose oxidase, glucose-6phosphate-dehydrogenase, hexokinase, glucuronidase, phosphotriesterase, superoxide dismutase, tyrosinase, urease, carbonic anhydrase, luciferase, lipase, etc. For a recently published review, see Walde \& Ichikawa, 2001). Much more limited is the progress in coentrapping several enzymes inside liposomes. After a pioneering study of Chang (1987) on cycling enzymatic routes inside non-lipid compartments (for example, the coupled system: urease, glutamate dehydrogenase, glucose dehydrogenase, glutamate-pyruvate transaminase), more recent approaches have been based on liposomes and polymersomes. Typical examples are glucose oxidase and horseradish peroxidase inside liposomes (Hill et al., 1997; Kaszuba \& Jones, 1999) or polymersomes (Delaittre et al., 2009; van Dongen et al., 2009), possibly with the involvement of a third enzyme (a lipase). The other system that has received attention is the couple bacterhodopsin/ ATP synthase (both membrane proteins) that have been reconstituted in liposomes at the aim of producing ATP after irradiation (Freisleben et al., 1995; Pitard et al., 1996; Choi and Montemagno, 2007). With respect to the control of vesicle membrane permeability, it is worth mentioning the increase of passive permeability of detergent-doped membranes (the concentration of detergent is below the lytic regime, Oberholzer et al., 1999; Treyer et al., 2002), and the use of $\alpha$-hemolysis (Noireaux \& Libchaber, 2004) or porines (Graff et al., 2001; Vamvakaki et al., 2005; Yoshimoto et al., 2005) as channel-forming agents. 
A

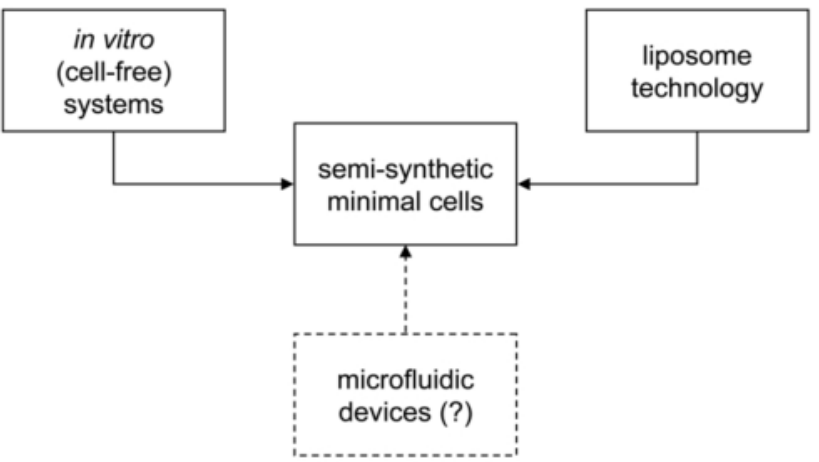

B

0. The basics

Liposome preparation and manipulation

Encapsulation of solutes

Detection methods

\title{
1. Enzyme reactions inside liposomes
}

One enzyme reactions

Multi-enyme reactions and cycles

Control of membrane permeability

\section{Reactions involving nucleic acids}

\author{
Transcription \\ Translation \\ Coupled transcription and translation \\ DNA replication \\ Ribosome production
}

3. "Core and shell" reproduction

Self-reproduction of "core" components

Lipid synthesis

Liposome growth and division

\section{Toward complex functions}

\section{Omeostatic regime \\ Energy production \\ Control of gene expression \\ Genetic circuits \\ Sensing and communication}

Fig. 3. Operative aspects of semi-synthetic minimal cell construction. (A) Technique currently involved for the production of minimal cells, mainly based on cell-free systems and liposome technology; the possible emerging role of microfluidic devices has been emphasized. (B) A possible roadmap for the stepwise construction of minimal cell models of increasing complexity. 
The next step along the road map for SSMC construction is the realization of nucleic acidbased reactions inside liposomes. These have been already carried out, as in the case of DNA synthesis (PCR inside liposomes, Oberholzer et al., 1995), DNA transcription (RNA synthesis, Tsumoto et al., 2001), RNA replication (Kita et al., 2008), and the coupled transcription/translation reactions (protein synthesis). In particular, the protein synthesis is currently the most well studied reaction inside liposomes (for references, see paragraph $\mathrm{Nr}$. 6). The current interest in protein synthesis fits well with the fact that this "module" is the most important for minimal cell construction, as also evident from the minimal genome analysis. The goal of ribosome production inside liposomes has not been reached, although some preliminary attempts have been anticipated (Jewett and Church, unpublished data presented at the $4^{\text {th }}$ Synthetic Biology conference, Hong Kong 2008).

By further increasing the complexity of minimal cell models, one can think to move to cyclic reactions, where the focus is on the regeneration of cell components. These can be distinguished between "core" components (DNA, RNA, ribosomes) and "shell" components (lipids). Clearly, for a successful cell reproduction, both core and shell parts should be generated from inside, possibly in coordinate manner. Early enzyme-catalyzed attempts for synthesizing lipids inside liposomes have been reported (Schmidli et al., 1991). Kuruma et al. (2008) have recently updated this research by expressing the enzymes of interests (two acyl transferases) from the corresponding DNA sequences (see below). The ultimate goal of core-and-shell reproduction is the observation of SSMCs growth and division as it happens in natural cells, clearly with a reduced efficiency.

Finally, it is possible to conceive compartimentalized molecular systems that display really complex dynamics such as homeostasis (for a simple example, see Zepik et al., 2001), sensing and communication (Gardner et al., 2009), energy production, control of genetic transcription, for example thanks to genetic circuitry (Noireaux et al., 2003; Kim \& Winfree, 2011).

\section{The technology for building minimal cells}

As stated before, the current SSMC technology is based on liposome technology and on cellfree systems. Essentially, the critical point is how to insert - possibly under control - the desired solutes inside lipid vesicles.

Let us start to consider the liposome technology. In principle there are three ways to operate (Fig. 4). The simplest approach consists into the spontaneous vesicle formation in a solution containing all solutes of interest (Fig. 4A). Currently, this is the most used procedure, and involves different preparation methods (lipid film hydration, freeze-dried liposome rehydration, ethanol injection (New, 1990). Current drug delivery technology, which is the most advanced branch of liposome technology, is also based on the spontaneous formation of solute-filled liposomes (only in the special case of weak bases an "active" loading method has been developed, Haran et al., 1993). In general terms, the apparently simple process described in Fig. 4A is still not well understood, due to the complexity of solute/membrane interactions and to not well-known subtle effects deriving from the interplay of chemical and physical factors during the vesicle formation. In fact, it has been recently discovered that a large heterogeneity exist in a population of vesicles prepared by these methods (Dominak \& Keating, 2007; Lohse et al., 2008). A clear-cut evidence of superconcentration of proteins inside lipid vesicles has been reported in the case of ferritin (Luisi et al., 2010). 
A second approach is described in Fig. $4 \mathrm{~B}$ and consists into the physical insertion of the solutes of interest inside a large vesicle (giant vesicle), by means of microinjection methods. This technique was developed in the Nineties (Wick et al., 1996; Bucher et al., 1998; Fischer et al., 2002) and offer the unique possibility of a total control of vesicle composition, but it could be hindered by technical difficulties, and by the fact that only a limited number of vesicles can be prepared and observed.
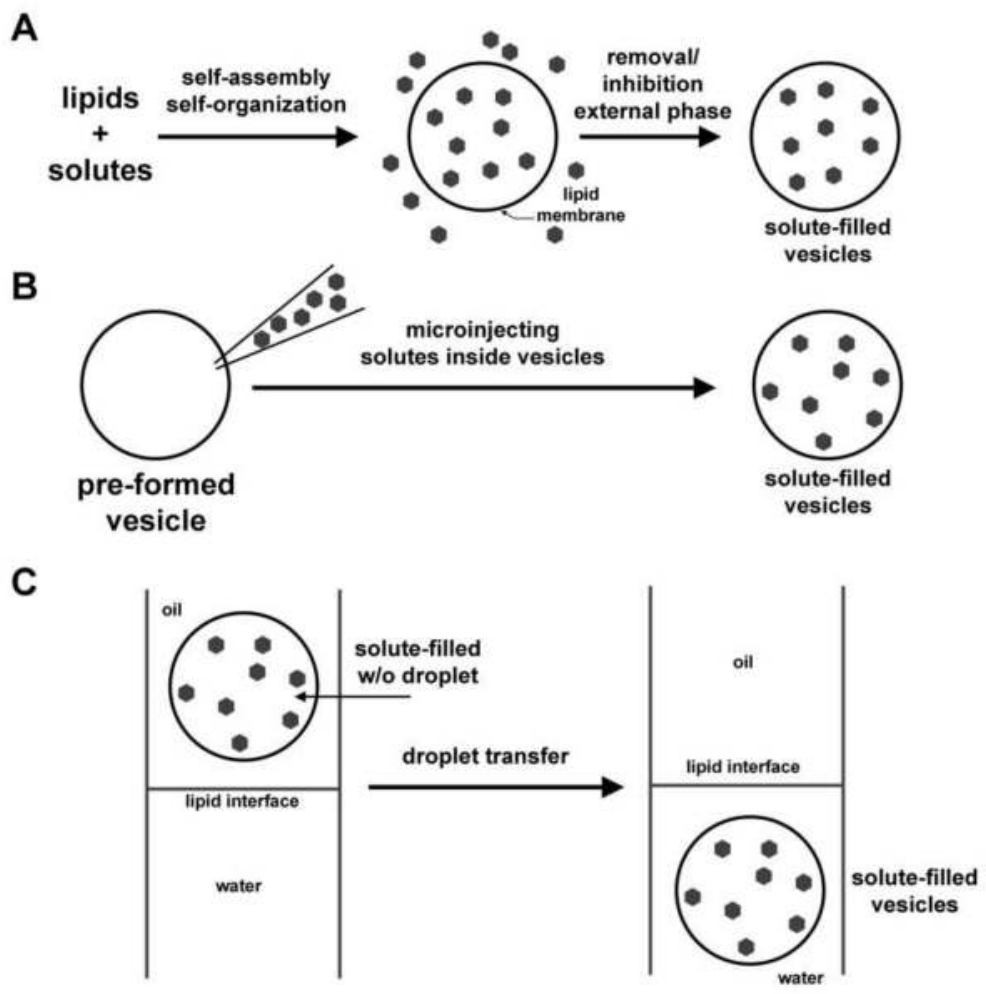

Fig. 4. Basic concepts for minimal cell constructions. (A) Liposomes are formed in a solution containing the solutes of interest; some liposomes will contain all required components. The external environment is quenched or changed in order to follow internalized reactions. (B) A microinjection procedure (for giant vesicles only) could allow the direct insertion of the mixture of interest into pre-formed vesicles. This procedure is clearly time-consuming and allows the study of a limited number of semi-synthetic minimal cells. (C) A very promising method for generating solute-filled vesicles starts from solute-filled water-in-oil droplets (which are easy to prepare) and transform them into giant vesicles according to a recently developed method (Pautot et al., 2003ab).

A third approach (Fig. 4C) is instead innovative and it is based on the recent success in preparing giant vesicles from water-in-oil droplets (Pautot et al., 2003ab). Some SSMC work has already be done by preparing vesicles with this method (Yamada et al., 2006; Pontani et al., 2009; Saito et al., 2009). Firstly, solutes are emulsified in a hydrocarbon solvent 

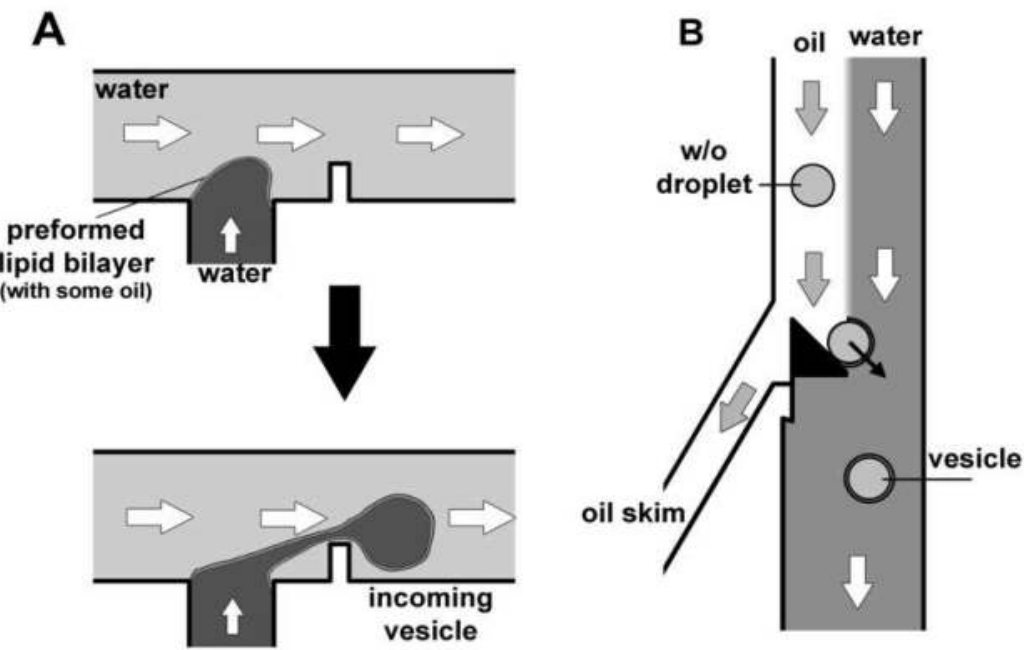

Fig. 5. Generation of giant vesicles in microfluidic devices. (A) The internal water phase (dark gray) is forced to flow into a microchannel containing the external water phase (light gray). Due to the presence of previously formed bilayer (possibly containing some oil), the two phases do not mix, and the lipid interphase is stretched to form a spherical vesicle that breaks after passage over an obstacle. Adapted with minor modifications (redrawn of the essential step of vesicle formation, removal of some details), from Ota et al., (2009), with permission from Wiley. (B) A microfluidic-generated water-in-oil droplet flow is tangentially poured near a water phase (dark gray) running in the same direction; lipids accumulate along the oil-water interface. An obstacle separate the oil flow from the aqueous flow forcing the water-in-oil droplet to cross the oil/water interface and form a vesicle, as shown in Fig. 4C. Adapted with minor modifications (redrawn of the essential step of vesicle formation, removal of some details), from Matosevic \& Paegel (2011), with permission from the American Chemical Society.

containing lipids. This brings to the formation of lipid-stabilized water-in-oil droplets, where lipids are oriented with the polar head-groups toward the droplet core, and with the tails toward the apolar solvent. A second lipid-containing apolar solution is stratified over an aqueous phase, so that a lipid interface is spontaneously generated at the oil-water interface. When a water-in-oil droplet crosses the water-oil interface, it becomes covered by a second lipid layer, and is then transformed into a giant vesicle when reaches the aqueous phase (on the bottom). The process is enhanced by centrifugation, taking advantage of the higher water density when compared with hydrocarbons. In this way, solutes initially present in the water-in-oil droplets (where 100\% compartmentalization is easy to achieve) are found inside giant vesicles. This methodology has been recently implemented in microfluidic devices.

The use of microfluidic devices seems very promising in SSMC technology, although not well developed when compared with the amount of work done with water-in-oil droplets. Here the advantage should be the control of vesicle production (uniform size, morphology, and lamellarity) and especially the control of vesicle content. Two interesting example of pioneering research are shown in Fig. 5. In the first case (Fig. 5A) giant vesicles have been 


\begin{tabular}{|c|c|c|c|}
\hline Component & Conc. & Component & Conc. \\
\hline Translation factors & & ProRS & $1300 \mathrm{U} / \mathrm{mL}$ \\
\hline IF1 & $2.7 \mu \mathrm{M}$ & SerRS & $1900 \mathrm{U} / \mathrm{mL}$ \\
\hline IF2 & $0.4 \mu \mathrm{M}$ & ThrRS & $1300 \mathrm{U} / \mathrm{mL}$ \\
\hline IF3 & $1.5 \mu \mathrm{M}$ & TrpRS & $630 \mathrm{U} / \mathrm{mL}$ \\
\hline EF-G & $0.26 \mu \mathrm{M}$ & TyrRS & $630 \mathrm{U} / \mathrm{mL}$ \\
\hline EF-Tu & $0.92 \mu \mathrm{M}$ & ValRS & $3100 \mathrm{U} / \mathrm{mL}$ \\
\hline EF-Ts & $0.66 \mu \mathrm{M}$ & & \\
\hline RF1 & $0.25 \mu \mathrm{M}$ & Other enzymes & \\
\hline RF2 & $0.24 \mu \mathrm{M}$ & MTF & $4500 \mathrm{U} / \mathrm{mL}$ \\
\hline RF3 & $0.17 \mu \mathrm{M}$ & Ribosomes & $1.2 \mu \mathrm{M}$ \\
\hline \multirow[t]{2}{*}{ RRF } & $0.5 \mu \mathrm{M}$ & Creatine kinase & $4 \mu \mathrm{g} / \mathrm{mL}$ \\
\hline & & Myokinase & $3 \mu \mathrm{g} / \mathrm{mL}$ \\
\hline $\begin{array}{l}\text { Amino acyl-tRNA synthetases } \\
\text { (RSs) }\end{array}$ & & $\begin{array}{l}\text { Nucleoside diphosphate } \\
\text { kinase }\end{array}$ & $1.1 \mu \mathrm{g} / \mathrm{mL}$ \\
\hline AlaRS & $1900 \mathrm{U} / \mathrm{mL}$ & Pyrophosphatase & $2 \mathrm{U} / \mathrm{mL}$ \\
\hline ArgRS & $2500 \mathrm{U} / \mathrm{mL}$ & T7 RNA polymerase & $10 \mu \mathrm{g} / \mathrm{mL}$ \\
\hline AsnRS & $20 \mathrm{mg} / \mathrm{mL}$ & & \\
\hline AspRS & $2500 \mathrm{U} / \mathrm{mL}$ & Energy sources & \\
\hline CysRS & $630 \mathrm{U} / \mathrm{mL}$ & ATP & $2 \mathrm{mM}$ \\
\hline GlnRS & $1300 \mathrm{U} / \mathrm{mL}$ & GTP & $2 \mathrm{mM}$ \\
\hline GluRS & $1900 \mathrm{U} / \mathrm{mL}$ & СТP & $1 \mathrm{mM}$ \\
\hline GlyRS & $5000 \mathrm{U} / \mathrm{mL}$ & UTP & $1 \mathrm{mM}$ \\
\hline HisRS & $630 \mathrm{U} / \mathrm{mL}$ & Creatine phosphate & $20 \mathrm{mM}$ \\
\hline IleRS & $2500 \mathrm{U} / \mathrm{mL}$ & & \\
\hline LeuRS & $3800 \mathrm{U} / \mathrm{mL}$ & Other components & \\
\hline LysRS & $3800 \mathrm{U} / \mathrm{mL}$ & 20 amino acids & $0.3 \mathrm{mM}$ \\
\hline MetRS & $6300 \mathrm{U} / \mathrm{mL}$ & $\begin{array}{l}\text { 10-formyl-5,6,7,8- } \\
\text { tetrahydrofolic acid }\end{array}$ & $10 \mathrm{mg} / \mathrm{mL}$ \\
\hline PheRS & $1300 \mathrm{U} / \mathrm{mL}$ & tRNAmix (Roche) & 56 Abs260 \\
\hline
\end{tabular}

*The components are solubilized in $50 \mathrm{mM}$ HEPES-KOH pH 7.6; $100 \mathrm{mM}$ potassium glutamate, $13 \mathrm{mM}$ magnesium acetate, $2 \mathrm{mM}$ spermidine, $1 \mathrm{mM}$ DTT. One unit of activity was defined as the amount of enzyme that catalyzes the formation of 1 pmol of amino acyl-tRNA in $1 \mathrm{~min}$.

Table 2. Composition of the PURE system.* Adapted from Shimizu et al. (2005), with permission from Elsevier. 
produced from two aqueous phases separated by a pre-formed lipid-rich micro-interface (Ota et al., 2009). The gentle flow of internal aqueous phase produces an elongated compartment that eventually breaks to give a giant vesicle. The proper design of an obstacle along the flow is essential to observe the desired pattern. Giant vesicles of average diameter $16.5 \mu \mathrm{m}( \pm 3.7 \%)$ are produced. In the second case (Fig. 5B), the droplet transfer method has been implemented in a microfluidic channel (Matosevic \& Paegel, 2011). Water-in-oil droplets, also generated within the microfluidic device tangentially flows against an aqueous phase which will constitute the external vesicle phase. A properly designed obstacle forces each water-in-oil droplet to cross the oil/water interface and become transformed into a vesicle, whereas the excess oil ends in a side channel. Vesicles with size from 20 to $70 \mu \mathrm{m}$ can be generated, be vesicle size being controlled by the water-in-oil droplet size.

The second aspect to discuss is the in vitro cell-free technology. In the case of simple molecular systems, such as one enzyme-reaction or simple standardized sets (e.g., PCR reactants), it is clear that the experimenter perfectly controls the nature of the solute mix to be entrapped inside lipid vesicles. Different is the case of quite complicated mixtures as the whole transcription-translation kit. Early research on protein synthesis inside liposomes has been done by encapsulating home-made or commercial cell extracts (e.g., Escherichia coli extracts). For example, home-made S30 E. coli extracts, enriched of T7 RNA polymerase and in the presence of a DNA plasmid, were used to demonstrate for the first time the expression of functional green fluorescent protein (GFP) inside vesicles (Yu et al., 2001). Although successful, this approach - that was used by several researchers, has an intrinsic limitation. In fact, a cell extract can be compared to a "black box", in the sense that its chemical composition and the concentrations of the species are not known exactly. Ideally, since one would like to investigate the activity just as a function of the relative composition and concentration of the components, a more detailed knowledge of the protein synthesis kit would be advisable. In 2001, the group of Takuya Ueda at the Tokyo University has formulated a "reconstituted" cell-free transcription and translation system from purified $E$. coli components, named PURE system (Protein synthesis Using Recombinant Elements) (Shimizu et al., 2001). The composition of this kit is shown in Table 2. The PURE system contains 9 translation factors, 20 aa-tRNA synthetases (aaRSs), 6 additional enzymes (also needed for energy regeneration), ribosomes, tRNAs, and low molecular weight compounds. There are 36 different purified macromolecular compounds, and presumably 46 different tRNAs (Dong et al., 1996), for a total of 82 different macromolecules. If we sum the template DNA it results that 83 different compounds are involved in coupled transcription/translation reactions (prokaryote ribosomes consists in 3 rRNAs and 55 ribosomal proteins, and therefore the overall number of different macromolecular sequences in the PURE system actually sums up to 141).

Notice that for synthesizing a protein inside liposomes, these 83 different macromolecules (at least 1 molecule of each species) should be co-entrapped in the liposome. The probability of such occurrence has been calculated on the basis of Poisson distribution, as a function of vesicle size (Souza et al., 2009), and assumes an experimentally significant value $(>5 \%)$ for vesicle diameters $>600 \mathrm{~nm}$.

Starting from 2006, the use of PURE system for synthesizing a protein inside liposomes has become the benchmark for SSMCs construction (Sunami et al., 2006; Murtas et al., 2007), even if the yield of produced protein is typically one third when compared with cell extracts (Hillebrecht \& Chong, 2008). Interestingly, we can look at the PURE system 
as a synthetic biology tool from the viewpoint of "standard biological parts" (http://partsregistry.org/Main_Page).

\section{Four commented examples of current research}

As stated above, the current state-of-the-art of SSMC research is the expression of functional proteins inside liposomes. This very specific research area has already a rich chronology of reports, starting from the pioneering study of Oberholzer et al. (1999), who synthesize poly(Phe) inside vesicles starting from the corresponding messenger poly(U). Several reviews have been compiled to discuss the advancement in the field (Luisi et al., 2006; Chiarabelli et al., 2009; Stano \& Luisi, 2010b), so that these aspects will not be repeated here. Rather, here we would like to comment four very relevant studies done in the last years, namely: (i) genetic cascade reaction inside liposomes; (ii) inside-vesicle production of a pore forming compound; (iii) synthesis of membrane enzymes (lipid-producing) inside liposomes; and (iv) RNA replication by RNA-encoded Q $\beta$-replicase.

The first case to discuss is a work from the Yomo group in Osaka, see Fig. 6A (Ishikawa et al., 2004). In this work the authors designed a two-stages cascade reaction inside liposomes. In particular the idea to have a DNA plasmid encoding for two proteins, namely T7 RNA polymerase and the green fluorescent protein (GFP). The corresponding genes, however, were under different promoters (SP6 and T7, respectively), so that the following cascade genetic reactions could happen. The plasmid was mixed with cell-free extracts enriched with SP6 RNA polymerase. This first polymerase acts on the first gene (SP6-t7_rna_polymerase) so that, after transcription, the T7RNA polymerase is effectively produced. In turn, this second polymerase acts on the second gene (T7- $g f p$ ), which ultimately gives the fluorescent protein, which was revealed via flow cytometry. Interestingly, this is the first case of controlled protein synthesis inside liposomes, not by transcription factors (this goal has not been reached yet), but by switching on the production of RNA polymerase.

The second interesting case comes from the Libchaber laboratory in New York, see Fig. 6B (Noireaux \& Libchaber, 2004). The authors designed a lipid vesicle containing the gene of $\alpha$ hemolysin (from Staphylococcus aureus). After the synthesis of $\alpha$-hemolysin by a cell-free cell extract, encapsulated into vesicles, the hemolysin spontaneously self-assembles into a heptamer on the lipid membrane, creating a pore (cut-off ca. $3 \mathrm{kDa}$ ). Thanks to its peculiar size, the pore allows the exchange of low molecular-weight compounds of the transcriptiontranslation kit (amino acids, nucleotides, etc.), without releasing large macromolecules. In this way, a long-lived "bioreactor" was created, capable of expressing proteins for ca. 100 hours, whereas in the absence of the pore, the reaction stops after ca. 4 hours (for this study, a fusion GFP-hemolysin protein was created). Interestingly, it was also shown that the coexpression of $\alpha$-hemolysin and GFP as two separated proteins was possible.

The third case comes from our laboratory in Rome, see Fig. 7A (Kuruma et al. 2009). This work was inspired by a previous study done on lipid-synthesizing enzymes inside vesicles, at the aim of creating a lipid-producing liposome (Schmidli et al., 1991). The route consisted into four enzyme-catalyzed steps, namely, from glycerol-3-phosphate (G3P) to lysophosphatidic acid (LPA), to phosphatidic acid (PA), to diacylglycerol, to phosphatidylcholine (PC). The 1991 work consisted in inserting the four enzymes that catalyzes this route into lipid vesicles and observe the production of PC starting from G3P and acylcoenzymes A. However the efficient production of PC was observed only in the case of short chain acyls, and the yield was around 10\%. In the work of Kuruma et al. (2009) 

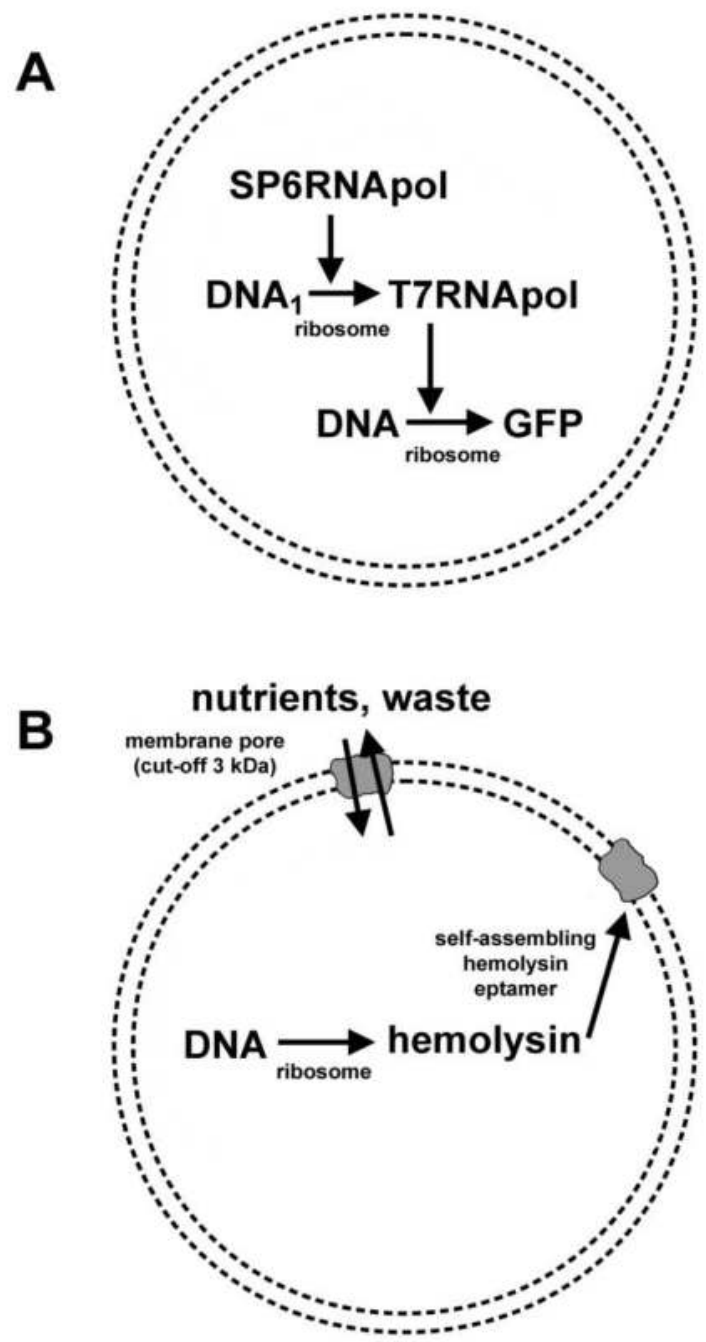

Fig. 6. Two remarkable examples of semi-synthetic minimal cell construction. (A) Genetic cascade reactions inside liposomes. SP6 RNA polymerase transcribes the mRNA of T7 RNA polymerase, which is then translated to give the functional protein. In turn, the newly formed T7 RNA polymerase transcribes the mRNA of GFP, which is then translated to give the fluorescent protein (Ishikawa et al., 2004). (B) $\alpha$-Hemolysin, produced inside a giant vesicle from its DNA sequence, self-assembles into an heptamer which is a pore on the phospholipid membrane. Its low cutoff $(3 \mathrm{kDa})$ allows the exchange of low molecularweight solutes (entrance of energy-rich compounds, release of exhausted compounds) without releasing the internal macromolecular components (RNA polymerase, ribosomes, etc.). In this way the production of a marker protein (GFP) proceeded continuously for 4 days (Noireaux \& Libchaber, 2004). 




B

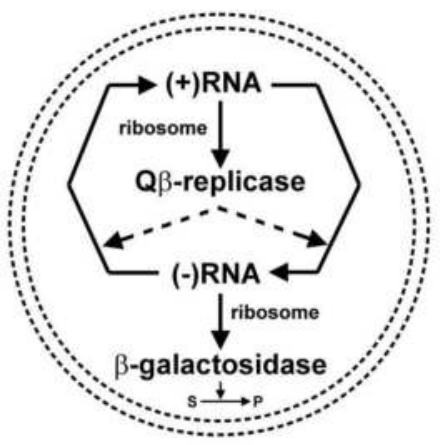

Fig. 7. Two remarkable examples of semi-synthetic minimal cell construction. (A) The two genes codifying for glycerol-3-phosphate acyltransferase (GPAT) and lysophosphatidic acid acyltransferase (LPAAT) have been co-entrapped into lipid vesicles with a cell-free protein synthesis kit. The two proteins, which - on the basis of their solubility - should be an integral membrane protein and a membrane associated one, respectively, catalyse the formation of 1-palmitoyl-2-oleoyl-sn-glycero-3-phosphatidic acid (POPA) from glycerol-3phosphate (G3P) and palmitoyl- and oleoyl-coenzimeA (C16CoA, and C18:1CoA, respectively), through the intermediate lysophosphatidic acid (LPA). Notice that the membrane composition is a key factor for realizing a functional system (POPC: 1-palmitoyl2-oleoyl-sn-glycero-3-phosphatidylcholine; POPE: 1-palmitoyl-2-oleoyl-sn-glycero-3phosphatidylethanolamine; POPG: 1-palmitoyl-2-oleoyl-sn-glycero-3-phosphatidylglycerol; CL: cardiolipin) (Kuruma et al., 2009). (B) Starting from Q $\beta$-replicase-codifying (+)RNA strand and cell-free protein expression system, the production of $Q \beta$-replicase was carried out inside liposomes, so that the complementary (-)RNA strand is produced from nucleotides and (+)RNA template. In turn, (-)RNA acts as a template for the Q $\beta$-replicase catalyzed (+)RNA strand synthesis. The correct production of (-)RNA is confirmed by the fact that it is designed to codify for $\beta$-galactosidase, whose ribosomal production was revealed by the increase of fluorescence due to the action of $\beta$-galactosidase on a fluorogenic substrate. This is an example of self-encoding genetic material, which codifies for its production inside lipid compartments (Kita et al., 2008). 
a different approach was tested. In particular the genes for the first two enzymes, called glycerol-3-phosphate acyltransferase (GPAT) and lysophosphatidic acid acyltransferase (LPAAT), were co-entrapped with the PURE system inside lipid vesicles of proper membrane chemical composition. The latter was a critical parameter because the lipids used to build the liposome should: (1) form good compartments, (2) avoid chemical interference with the PURE system, (3) favor the folding, the membrane association and the activity of the two enzymes, which were, respectively, integral membrane enzyme and membrane associated enzyme (estimated on the basis of their solubility). It was shown that the two enzymes could be synthesized inside vesicles, although they required different redox environments (dithiothreitol vs oxidized glutathione) for acquiring the corresponding function. Despite this limitations and the low yield of functional protein synthesized inside liposomes, it was indeed possible to observe, in a discontinuous coupling assay, the production of a small amount 1-palmitoyl-2-oleoyl-sn-glycero-3-phosphatidic acid (POPA) from G3P and palmitoylCoA and oleoylCoA. Unfortunately, the low POPA yield did not allow a vesicle morphological change (for example, vesicle growth).

Finally, an important example of SSMC work comes again from the laboratory of Yomo and coworkers (Fig. 7B), and concerns the replication of RNA inside vesicles, operated by an enzyme (the $Q \beta$-replicase) whose production was ultimately encoded in the RNA sequence itself (Kita et al., 2008). The aim of this study was the coupling between informationcarrying molecules and the production of molecular machinery that replicate the information (RNA that codifies for an enzyme whose role is to replicate RNA). At this aim, a template $(+)$ RNA strand was coencapsulated with the reconstituted transcription/translation kit. Its translation gives the functional enzyme $Q \beta$-replicase, that in turn replicate the template (+)RNA into the complementary strand (-)RNA (and viceversa). In a more complex design, the $\beta$-galactosidase, encoded on the (-)RNA strand was also successfully expressed, and its function verified by the production of a fluorescent product from a fluorogenic substrate.

\section{Potential applications of minimal semi-synthetic cells and other microcompartimentalized systems}

It is true that at the current stage the SSMC research appears still at its infancy, but it is also possible to devise some potential applications. Perhaps, one of the most interesting one has been proposed by LeDuc et al. (2007) (see also Zhang et al., 2008). The authors have proposed a potential application of a cell-like construction as "nanofactory" (Fig. 8). Shortly, inspired by the current research on liposomes as vehicle for drug delivery of drugs, and on their targeting based on antibody-functionalization, a kind of minimal cell could be constructed from a lipid shell and internalized metabolic/genetic circuits. Thanks to the surface recognition by specific intermolecular interactions, the "nanofactory", once injected in the body could find the target tissue and accumulate in the nearby. Once sit near the target tissue, thanks to membrane permeability an externally present chemical trigger might induce a cascade internal reaction that ultimately produce a toxic drug for the tissue, so that an in situ produced drug can act locally with minimal damage for other body parts.

A second interesting aspect is related to potential sensing capability of SSMCs. The possible applications of lipid vesicles as membrane models for toxicological assessment of xenobiotics has been described (Zepik et al., 2008). By combining surface-bound receptors with internalized triggered response, SSMCs biosensors could be constructed for sensing 


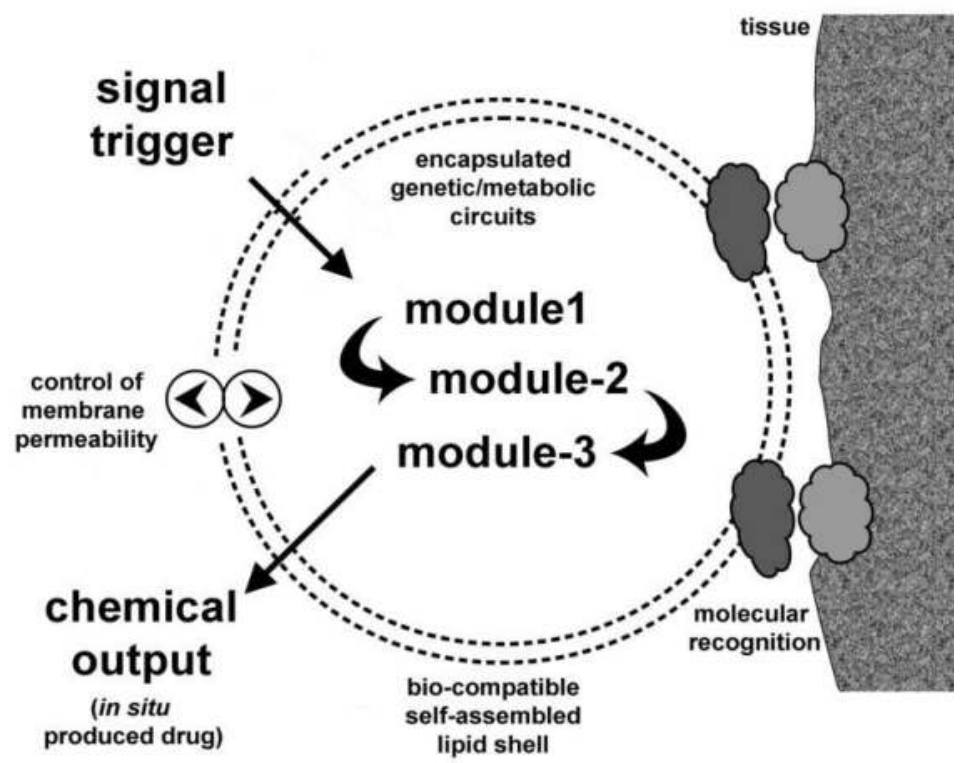

Fig. 8. A potential use of semi-synthetic minimal cells as drug nanofactories. The synthetic cell, injected in the body, might recognize specific tissues by means of surface-exposed antibodies, whereas its internal content consists into genetic/metabolic modules capable of detecting an externally present chemical trigger (a specific molecule that characterizes the tissue of interest), and work coordinately work to produce a chemical output, for example a drug. Entrance and release of compounds is achieved by controlling the membrane permeability by means of proteins or by changing lipid composition. Redrawn on the basis of a published figure (Le Duc et al., 2007).

different kind of molecules. An interesting study on the use of lipid vesicles for sensing odorants has been reported (Takeuchi et al., 2011). Although the core mechanism was based on chemical transformation, it is possible to think to similarly working biomolecular networks. From the technical viewpoint, the technological ability to generate vesicle arrays will certainly be important for exploiting SSMCs sensing (Christensen \& Stamou, 2010).

In addition to long-term prospects for biotechnology, as the use of minimalized strains of bacteria-like objects for industrial applications, the construction of SSMCs also has a profound implication in basic science. First of all, it helps to demonstrated, if still needed, that a minimal living organism can be constructed from separated non-living parts, that is equivalent to say that life is an emerging property of a self-organized spatial-functional molecular ensemble, where the fact of being alive stems from the dynamical relations between components, rather than their chemical nature. All this is resonant with the autopoiesis introduced in the second paragraph. Secondly, and here we find the field where the SSMCs comes from, the construction of such structures has great relevance for origin of life studies. In this case the focus is shifted from the sophistication of biotechnology application to the assembly process itself, where the particular nature of used molecules merely represents a model of primitive solutes. What is important is the demonstration that sets of free molecules and lipids spontaneously assemble into a cell-like particle, and that 
functions - initially not present in the bulk phase, become characteristic of compartmentalized systems. For example, the recently reported discovery (Luisi et al., 2010) of self-concentration of proteins (and ribosomes, Souza et al., submitted manuscript) inside liposomes points to the emergence of functional cells from diluted compounds. In other words, the formation of liposomes implies the formation of concentrated/segregated phase that might exhibit enhanced functionality when compared with the analogous system in bulk (see also Souza et al., 2009). In this way, SSMCs studies might provide a rational explanation to the spontaneous emergence of living cells in primitive times.

In conclusion, the investigation on SSMCs is in a flourishing phase, and we are convinced that the development of this technology will be of great value for basic and applied science.

\section{Acknowledgment}

I greatly thank Pier Luigi Luisi for inspiring this research and for stimulating discussions. Funding/networking agencies: SYNTHCELLS project (Approaches to the Bioengineering of Synthetic Minimal Cells, EU-FP6 043359), HFSP (RGP0033/2007-C), ASI (I/015/07/0), PRIN2008 (2008FY7RJ4), SynBioNT, and COST Systems Chemistry action (CM0703).

\section{References}

Bucher, P., Fischer, A., Luisi, P. L., Oberholzer, T. \& Walde, P. (1998). Giant Vesicles as Biochemical Compartments: The Use of Microinjection Techniques. Langmuir 14, 2712-2721.

Chang, M. T. S. (1987) Recycling of $\mathrm{NAD}(\mathrm{P})$ by multienzyme systems immobilized by microencapsulation in artificial cells. Met. Enzymology 136, 67-82.

Chiarabelli, C., Stano, P. \& Luisi, P. L. (2009). Chemical approaches to synthetic biology. Curr. Opin. Biotech. 20, 492-497.

Choi, H. J. \& Montemagno, C. D. (2007). Light-driven hybrid bioreactor based on proteinincorporated polymer vesicles. IEEE Trans. Nanotech. 6, 171-176.

Christensen, S. M. \& Stamou, D. G. (2010). Sensing-Applications of Surface-Based Single Vesicle Arrays. Sensors 10, 11352-11368.

De Lorenzo, V. \& Danchin, A. (2008). Synthetic biology: Discovering new worlds and new words. EMBO Rep. 9, 9.

Delaittre, G., Reynhout, I. C., Cornelissen, J. J. L. M. \& Nolte, R. J. M. (2009). Cascade reactions in an all-enzyme nanoreactor. Chem. Eur. J. 15, 12600-12603.

Dominak, L. M. \& Keating, C. D. (2007). Polymer Encapsulation within Giant Lipid Vesicles. Langmuir 23, 7148-7154.

Dong, H., Nilsson, L. \& Kurland, C. G. (1996) Co-variation of tRNA abundance and codon usage in Escherichia coli at different growth rates. J. Mol. Biol. 260, 649663.

Fehér, T., Papp, B., Pál, C. \& Pósfai, G. (2007). Systematic Genome Reductions: Theoretical and Experimental Approaches. Chem. Rev. 107, 3498-3513.

Fischer, A., Franco, T. \& Oberholzer, T. (2002). Giant Vesicles as Microreactors for Enzymatic mRNA Synthesis. ChemBioChem 3, 409-417.

Forster, A. C. \& Church, G. M. (2006). Towards synthesis of a minimal cell. Molecular Systems Biology 2, 45. 
Fraser, C. M., Gocayne, J. D., White, O. et al. (1995) The minimal gene complement of Mycoplasma genitalium. Science 270, 397-403.

Freisleben, H. J., Zwicker, K., Jezek, P., John, G., Bettin-Bogutzki, A., Ring, K. \& Nawroth, T. (1995). Reconstitution of bacteriorhodopsin and ATP synthase from Micrococcus luteus into liposomes of the purified main tetraether lipid from Thermoplasma acidophilum : proton conductance and light-driven ATP synthesis. Chem. Phys. Lip. 78, 137-147.

Gardner, P. M., Winzer, K. \& Davis, B. G. (2009). Sugar synthesis in a protocellular model leads to a cell signalling response in bacteria. Nature Chem. 1, 377-383.

Gibson, D. G., Glass, J. I., Lartigue, C., Noskov, V. N., et al. (2010). Creation of a bacterial cell controlled by a chemically synthesized genome. Science 329, 52-56.

Gil, R., Silva, F. J., Peretó, J. \& Moya, A. (2004). Determination of the core of a minimal bacteria gene set. Microbiol. Mol. Biol. Rev. 68, 518-537

Graff, A., Winterhalter, M. \& Meier, W. (2001). Nanoreactors from polymer-stabilized liposomes. Langmuir 17, 919-923.

Haran, G., Cohen, R., Bar, L. K. \& Barenholz, Y. (1993). Transmembrane ammonium sulfate gradients in liposomes produce efficient and stable entrapment of amphipathic weak bases. Biochim. Biophys. Acta 1151, 201-215.

Henry, C. S., Overbeek, R. \& Stevens, R. L. (2010). Building the blueprint of life. Biotechnol. J. 5, 695-704.

Hill, K. J., Kaszuba, M., Creeth, J. E. \& Jones, M. N.(1997). Reactive liposomes encapsulating a glucose oxidase-peroxidase system with antibacterial activity. Biochim. Biophys. Acta 1326, 37-46.

Hillebrecht, J. R. \& Chong, S. (2008). A comparative study of protein synthesis in in vitro systems: from the prokaryotic reconstituted to the eukaryotic extract-based. BMC Biotechnology 8, 58.

Ishikawa, K., Sato, K., Shima, Y., Urabe, I. \& Yomo, T. (2004). Expression of a cascading genetic network within liposomes. FEBS Lett. 576, 387-390.

Islas, S., Becerra, A., Luisi, P. L. \& Lazcano, A. (2004). Comparative genomics and the gene complement of a minimal cell. Orig. Life Evol. Biosph. 34, 243-256.

Kaszuba, M. \& Jones, M. N. (1999). Hydrogen peroxide production from reactive liposomes encapsulating enzymes. Biochim. Biophys. Acta 1419, 221-228.

Kim, J. \& Winfree, E. (2011). Synthetic in vitro transcriptional oscillators. Molecular Systems Biology 7, 465.

Kita, H., Matsuura, T., Sunami, T., Hosoda, K., Ichihashi, N., Tsukada, K., Urabe, I. \& Yomo, T. (2008). Replication of genetic information with self-encoded replicase in liposomes. ChemBiochem 9, 2403-2410.

Knoll, A.; Osborn, M. J.; Baross, J.; Berg, H. C.; Pace, N. R. \& Sogin, M. (eds.) (1999). Size limits of very small microorganisms. National Academic Press, Washington.

Kuruma, Y., Stano, P., Ueda, T. \& Luisi, P. L. (2009). A synthetic biology approach to the construction of membrane proteins in semisynthetic minimal cells. Biochim. Biophys. Acta 1788, 567-574.

LeDuc, P. et al. (2007). Towards an in vivo biologically inspired nanofactory. Nature Nanotech. 2, 3-7.

Lohse, B., Bolinger, P.-Y. \& Stamou, D. (2008). Encapsulation Efficiency Measured on Single Small Unilamellar Vesicles. J. Am. Chem. Soc. 130, 14372 -14373. 
Luisi, P. L., Allegretti, M., Souza, T., Steineger, F., Fahr, A. \& Stano, P. (2010). Spontaneous protein crowding in liposomes: A new vista for the origin of cellular metabolism. ChemBiochem 11, 1989-1992.

Luisi, P. L., Ferri, F. \& Stano, P. (2006). Approaches to semi-synthetic minimal cells: a review. Naturwissenschaften 93, 1-13.

Luisi, P. L.; Stano, P. (Eds.) (2011). The minimal cell. The Biophysics of Cell Compartment and the Origin of Cell Functionality. Springer, Dordrecht.

Matosevic, S. \& Paegel, B. M. (2011). Stepwise Synthesis of Giant Unilamellar Vesicles on a Microfluidic Assembly Line J. Am. Chem. Soc. 133, 2798-2800.

Morowitz, H. J. (1992). Beginning of Cellular Life. Metabolism Recapitulates Biogenesis. Yale University Press, New Haven.

Moya, A., Gil, R., Latorre, A., Peretó, J., Garcillán-Barcia, M. P. \& de la Cruz, F. (2009). Toward minimal bacterial cells: evolution vs. design. FEMS Microbiol. Rev. 33, 225-235.

Murtas, G., Kuruma, Y., Bianchini, P., Diaspro, A. \& Luisi, P. L. (2007). Protein synthesis in liposomes with a minimal set of enzymes. Biochem. Biophys. Res. Commun. 363, 12-17.

Mushegian, A. R. \& Koonin, E. V. (1996). A minimal gene set for cellular life derived by comparison of complete bacterial genomes. PNAS 93, 10268-10273.

New, R. R. C. (1990). Liposomes, a practical approach. IRL Press at Oxford University Press, Oxford.

Noireaux, V. \& Libchaber, A. (2004). A vesicle bioreactor as a step toward an artificial cell assembly. PNAS 101, 17669-17674.

Noireaux, V., Bar-Ziv, R. \& Libchaber, A. (2003). Principles of cell-free genetic circuit assembly. PNAS 100, 12672-12677.

Oberholzer, T., Albrizio, M. \& Luisi, P. L. (1995). Polymerase chain reaction in liposomes. Chem. \& Biol. 2, 677-682.

Oberholzer, T., Meyer, E., Amato, I., Lustig, A. \& Monnard, P.-A. (1999). Enzymatic reactions in liposomes using the detergent-induced liposome loading method. Biochim. Biophys. Acta 1416, 57-68.

Oberholzer, T., Nierhaus, K. H. \& Luisi, P. L. (1999) Protein expression in liposomes. Biochem. Biophys. Res. Comm. 261, 238-241.

Ota, S., Yoshizawa, S. \& Takeuchi, S. (2009). Microfluidic Formation of Monodisperse, Cell-Sized, and Unilamellar Vesicles. Angew. Chem. Int. Ed. 2009, 48, 65336537.

Pautot, S., Frisken, B. J. \& Weitz, D.A. (2003a). Engineering asymmetric vesicles. PNAS 100, 10718-10721.

Pautot, S., Frisken, B. J. \& Weitz, D.A. (2003b). Production of Unilamellar Vesicles Using an Inverted Emulsion. Langmuir 19, 28702879.

Pitard, B., Richard, P., Dunarach, M., Girault, G. \& Rigaiud, J. L. (1996) ATP Synthesis by the F0F1 ATP synthase from Thermophilic bacillus PS3 reconstituted into liposomes with bacteriorhodopsin 1. Factors defining the optimal reconstitution of ATP synthases with bacteriorhodopsin. Eur. J. Biochem. 235, 769-778.

Pontani, L. L., van der Gucht, J., Salbreux, G., Heuvingh, J., Joanny J.-F. \& Sykes, C. (2009). Reconstitution of an Actin Cortex Inside a Liposome. Biophys. J. 96, 192-198. 
Saito, H., Kato, Y., La Berre, M., Yamada, A., Inoue, T., Yoshikawa, K. \& Baigl, D. (2009). Time-Resolved Tracking of a Minimum Gene Expression System Reconstituted in Giant Liposomes. ChemBioChem 10, 1640-1643.

Schmidli, P. K., Schurtenberger, P. \& Luisi, P. L. (1991). Liposome mediated enzymatic synthesis of phosphatidylcholine as an approach to self-replicating liposomes. J. Am. Chem. Soc. 113, 8127-8130.

Shimizu, Y., Inoue, A., Tomari, Y., Suzuki, T., Yokogawa, T., Nishikawa, K. \& Ueda, T. (2001). Cell free translation reconstituted with purified components. Nat. Biotechnol. 19, 751-755.

Shimizu, Y., Kanamori, T. \& Ueda, T. (2005). Protein synthesis by pure translation systems. Methods 36, 299-304.

Souza, T., Stano, P. \& Luisi, P. L. (2009). The minimal size of liposome-based model cells brings about a remarkably enhanced biological activity. ChemBiochem 10, 10561063.

Stano, P. \& Luisi, P. L. (2010a). Achievements and open questions in the self-reproduction of vesicles and synthetic minimal cells. Chem Comm. 46, 3639-3653.

Stano, P. \& Luisi, P. L. (2010b) Reactions in Liposomes. In: "Molecular Encapsulation: Organic Reactions in Constrained Systems" U. H. Brinker \& J.-L. Mieusset (eds.) Wiley. Pp. 455-492.

Sugiura, S., Kuroiwa, T., Kagota, T., Nakajima, M., Sato, S., Mukataka, S., Walde, P. \& Ichikawa, S. (2008). Novel Method for Obtaining Homogeneous Giant Vesicles from a Monodisperse Water-in-Oil Emulsion Prepared with a Microfluidic Device. Langmuir 2008, 24, 4581-4588.

Sunami, T., Sato, K., Matsuura, T., Tsukada, K., Urabe, I. \& Yomo, T. (2006). Femtoliter compartment in liposomes for in vitro selection of proteins. Analytical Biochem. 357, 128-136.

Takeuchi, T., Montenegro, J., Hennig, A. \& Matile, S. (2011). Pattern generation with synthetic sensing systems in lipid bilayer membranes. Chem. Sci. 2, 303-307.

Treyer, M., Walde, P. \& Oberholzer, T. (2002). Permeability Enhancement of Lipid Vesicles to Nucleotides by Use of Sodium Cholate: Basic Studies and Application to an Enzyme-Catalyzed Reaction Occurring inside the Vesicles. Langmuir 18, 10431050.

Tsumoto, K., Nomura, S. M., Nakatani, Y. \& Yoshikawa, K. (2001). Giant liposome as a biochemical reactor: transcription of DNA and transportation by laser tweezers. Langmuir 17, 7225-7228.

Vamvakaki, V., Fournier, D. \& Chaniotakis, N. A. (2005). Fluorescence detection of enzymatic activity within a liposome based nano-biosensor. Biosens. Bioelectr. 21, 384-388.

Van Dongen, S. F. M., Nallani, M., Cornelissen, J. J. L. M., Nolte, R. J. M. \& van Hest, J. C. M. (2009). A three-enzyme cascade reaction through positional assembly of enzymes in a polymersome nanoreactor. Chem. Eur. J. 15, 1107-1114.

Varela, F., Maturana, H. \& Uribe, R. (1974). Autopoiesis: the organization of living systems, its characterization and a model. BioSystems 5, 187-195.

Walde, P. \& Ichikawa, S. (2001). Enzymes inside Lipid Vesicles: preparation, reactivity and Applications. Biomolecular Engineering 18, 143-177. 
Walde, P., Cosentino, K., Hengel, H. \& Stano, P. (2010). Giant Vesicles: Preparations and Applications. ChemBioChem 11, 848-865.

Wick, R., Angelova, M., Walde, P. \& Luisi, P. L. (1996). Microinjection into giant vesicles and light microscopy investigation of enzyme-mediated vesicle transformations. Chem. E Biol. 3, 105-111.

Yamada, A., Yamanaka, T., Hamada, T., Hase, M., Yoshikawa, K. \& Baigl, D. (2006). Spontaneous Transfer of Phospholipid-Coated Oil-in-Oil and Water-in-Oil MicroDroplets through an Oil/Water Interface. Langmuir 22, 98249828.

Yoshimoto, M., Wang, S., Fukunaga, K., Fournier, D., Walde, P., Kuboi, R. \& Nakao, K. (2005). Novel immobilized liposomal glucose oxidase system using the channel protein OmpF and catalase. Biotechnol. Bioeng. 90, 231-238.

Yu, W., Sato, K., Wakabayashi, M., Nakatshi, T., Ko-Mitamura, E. P., Shima, Y., Urabe, I. \& Yomo, T. (2001). Synthesis of functional protein in liposome. J. Biosci. Bioeng. 92, 590-593.

Zepik, H. H., Bloechliger, E. \& Luisi, P. L. (2001). A Chemical Model of Homeostasis. Angew. Chemie Int. Ed. 40, 199-202.

Zepik, H. H., Walde, P., Kostoryz, E. L., Code, J. \& Yourtee, D. M. (2008). Lipid vesicles as membrane models for toxicological assessment of xenobiotics. Crit. Rev. Toxicol. $38,1-11$.

Zhang, Y.; Ruder, W. C. \& LeDuc. P. (2008). Artificial cells: building bioinspired systems using small-scale biology. Trends Biotech. 26, 14-20. 


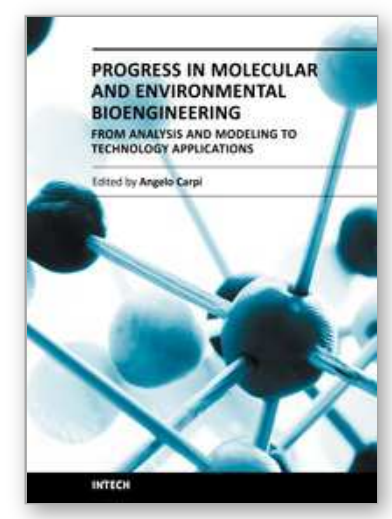

\author{
Progress in Molecular and Environmental Bioengineering - From \\ Analysis and Modeling to Technology Applications \\ Edited by Prof. Angelo Carpi
}

ISBN 978-953-307-268-5

Hard cover, 646 pages

Publisher InTech

Published online 01, August, 2011

Published in print edition August, 2011

This book provides an example of the successful and rapid expansion of bioengineering within the world of the science. It includes a core of studies on bioengineering technology applications so important that their progress is expected to improve both human health and ecosystem. These studies provide an important update on technology and achievements in molecular and cellular engineering as well as in the relatively new field of environmental bioengineering. The book will hopefully attract the interest of not only the bioengineers, researchers or professionals, but also of everyone who appreciates life and environmental sciences.

\title{
How to reference
}

In order to correctly reference this scholarly work, feel free to copy and paste the following:

Pasquale Stano (2011). Advances in Minimal Cell Models: a New Approach to Synthetic Biology and Origin of Life, Progress in Molecular and Environmental Bioengineering - From Analysis and Modeling to Technology Applications, Prof. Angelo Carpi (Ed.), ISBN: 978-953-307-268-5, InTech, Available from:

http://www.intechopen.com/books/progress-in-molecular-and-environmental-bioengineering-from-analysisand-modeling-to-technology-applications/advances-in-minimal-cell-models-a-new-approach-to-syntheticbiology-and-origin-of-life1

\section{INTECH}

open science | open minds

\author{
InTech Europe \\ University Campus STeP Ri \\ Slavka Krautzeka 83/A \\ 51000 Rijeka, Croatia \\ Phone: +385 (51) 770447 \\ Fax: +385 (51) 686166 \\ www.intechopen.com
}

\author{
InTech China \\ Unit 405, Office Block, Hotel Equatorial Shanghai \\ No.65, Yan An Road (West), Shanghai, 200040, China \\ 中国上海市延安西路65号上海国际贵都大饭店办公楼 405 单元 \\ Phone: +86-21-62489820 \\ Fax: $+86-21-62489821$
}


(C) 2011 The Author(s). Licensee IntechOpen. This chapter is distributed under the terms of the Creative Commons Attribution-NonCommercialShareAlike-3.0 License, which permits use, distribution and reproduction for non-commercial purposes, provided the original is properly cited and derivative works building on this content are distributed under the same license. 